\title{
Microstructure and Mechanical Properties of Mg-6Al-1Sn-0.3Mn Alloy Sheet Fabricated through Extrusion Combined with Rolling
}

\author{
Peng Peng ${ }^{1}$, Aitao Tang ${ }^{1,2, *}$, Xianhua Chen ${ }^{1,2}$, Jia She ${ }^{1,2, *}$, Shibo Zhou ${ }^{1}$, Jiangfeng Song ${ }^{1,2}$ \\ and Fusheng Pan 1,2,3 \\ 1 Department of Material Science, College of Materials Science and Engineering, Chongqing University, \\ Chongqing 400044, China; peng_pp@foxmail.com (P.P.); xhchen@cqu.edu.cn (X.C.); \\ zhoushibo1994@foxmail.com (S.Z.); jiangfeng.song@cqu.edu.cn (J.S.); fspan@cqu.edu.cn (F.P.) \\ 2 National Engineering Research Center for Magnesium Alloys, Chongqing University, \\ Chongqing 400044, China \\ 3 Chongqing Academy of Science and Technology, Chongqing 401123, China \\ * $\quad$ Correspondence: tat@cqu.edu.cn (A.T.); jiashe@cqu.edu.cn (J.S.); Tel.: +86-138-8317-3085 (A.T.); \\ +86-136-0817-4036 (J.S.)
}

Received: 30 July 2018; Accepted: 2 September 2018; Published: 5 September 2018

\begin{abstract}
Hot rolling was carried out in this study to modify the microstructures of an extruded $\mathrm{Mg}-6 \mathrm{Al}-1 \mathrm{Sn}-0.3 \mathrm{Mn}$ alloy sheet and investigate its effects on mechanical properties. After hot rolling, the grains and second phase of the extruded alloy sheet were remarkably refined, and the c-axis of a few grains was parallel to the transverse direction. The strength improvement was mainly attributed to the grain and $\mathrm{Mg}_{17} \mathrm{Al}_{12}$ particle refinement due to the Hall-Petch effect and the Orowan mechanism. The random orientation of the fine grains resulted in improving ductility and anisotropy.
\end{abstract}

Keywords: metallic and alloys; microstructure; mechanical properties

\section{Introduction}

Magnesium alloys, as the lightest conventional structural material, can deal with the regulations of energy conservation and environmental pollution [1]. However, their low strength and poor plastic properties at ambient temperature restrict their applications in industrial fields [2,3]. Enhancing the strength and ductility of magnesium alloys through chemical alloying and thermal processes is an effective way to expand the scope of their application [4].

According to previous studies [5-11], alloying elements are widely used to improve the tensile strength, plastic forming properties, and microstructures of magnesium alloys [12]. Wang et al. [13] reported that the addition of $\mathrm{Al}$ and $\mathrm{Sn}$ could enhance the ductility of $\mathrm{Mg}-\mathrm{Al}-\mathrm{Sn}$ alloys by reducing stack fault energies. Mg-9.8Sn-1.2Zn-1.0Al alloy, which consists of coarse and fine mixed grains with a typical basal texture, has a high tension-to-compression ratio (0.9) [12]. She et al. [14] developed $\mathrm{Mg}-\mathrm{xAl}-\mathrm{ySn}-0.3 \mathrm{Mn}$ serial alloys. The fully recrystallized microstructure of these alloys exhibits high strength that exceeds $300 \mathrm{MPa}$. Therefore, $\mathrm{Mg}-\mathrm{Al}-\mathrm{Sn}$ serial alloys are promising magnesium alloys.

The thermal process is an effective way to elevate the mechanical properties and isotropy of magnesium alloys, especially through the deformation method of extrusion and rolling $[15,16]$. Wang et al. [17] investigated the thermal processes in rolling for as-cast, cast-rolling, and as-extruded AZ91 alloy sheets. Their results showed that AZ91 alloy sheets subjected to extruded rolling with a reduction of $\sim 78.6 \%$ displayed the highest yield strength (YS, $248 \mathrm{MPa}$ ) and tensile strength (382 MPa) at room temperature. 
$\mathrm{Mg}-\mathrm{Al}-\mathrm{Sn}$ series alloys have clearly been comprehensively explored, and the results indicate that their mechanical properties are better than commercial magnesium alloys [18]. However, the performance of $\mathrm{Mg}-\mathrm{Al}-\mathrm{Sn}$ sheets is rarely investigated. In this study, the effects of the thermal process on the microstructure and mechanical properties of $\mathrm{Mg}-6 \mathrm{Al}-1 \mathrm{Sn}-0.3 \mathrm{Mn}$ alloy sheet are examined. The main work is aimed at investigating the microstructure evolution, mechanical properties, and anisotropy variation related to the initial-extruded and final-rolled $\mathrm{Mg}-6 \mathrm{Al}-1 \mathrm{Sn}-0.3 \mathrm{Mn}$ alloy sheets. Mn was added to remove Fe impurities.

\section{Materials and Methods}

In this study, a Mg-6Al-1Sn-0.3Mn (ATM610) alloy ingot of about $3 \mathrm{~kg}$ was prepared from a high-purity $\mathrm{Mg}$ (99.98 wt \%), pure Al, Pure Sn and Mg-3 wt \% Mn master alloy. The alloying components were completely melted in a steel crucible under the protective atmosphere of mixed gas $\mathrm{CO}_{2}$ and $\mathrm{SF}_{6}$ at $\sim 720^{\circ} \mathrm{C}$, and then poured into a steel mold with a diameter of $80 \mathrm{~mm}$, and a height of $200 \mathrm{~mm}$. The mold had been preheated at $300^{\circ} \mathrm{C}$ before pouring. The solution treatment of as-cast billet was performed at $420^{\circ} \mathrm{C}$ for $24 \mathrm{~h}$ followed by immediate water-cooling. After being preheated at $350^{\circ} \mathrm{C}$ for $2 \mathrm{~h}$, the solution treated billet was hot extruded to a $3 \mathrm{~mm} \times 60 \mathrm{~mm}$ sheet in an XJ-500 horizontal extruder (Yuanchang Machinery, Wuxi, China) at $350{ }^{\circ} \mathrm{C}$. The extrusion speed and extrusion rate were $1 \mathrm{~m} / \mathrm{min}$ and 28:1, respectively. The extruded sheet was rolled from $3 \mathrm{~mm}$ to $1 \mathrm{~mm}$ in thinness by 5 passes at $400{ }^{\circ} \mathrm{C}$. The total reduction of $66.7 \%$ was made up of 5 passes, which reduced by $20 \%$ per pass. The intermediate annealing process was at $400{ }^{\circ} \mathrm{C}$ for $30 \mathrm{~min}$. After the rolling process, the ATM610 sheet was annealed at $250{ }^{\circ} \mathrm{C}$ for $10 \mathrm{~min}, 30 \mathrm{~min}, 60 \mathrm{~min}$, and $120 \mathrm{~min}$ in a box-type resistance furnace. The main technological process of the ATM610 alloy sheet is displayed in Figure 1a.

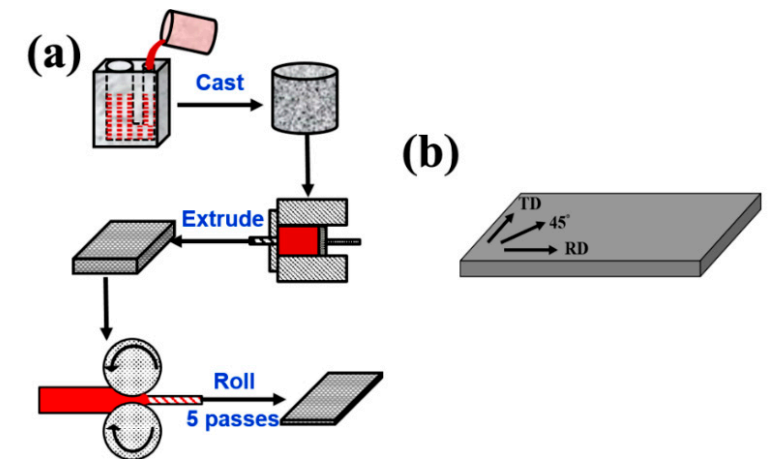

Figure 1. The preparation schematic of the ATM610 alloy sheet: (a) technological process and (b) machine directions.

The mechanical test samples were prepared from the extruded/rolled ATM610 alloy sheet along the three different directions $\left(0^{\circ}, 45^{\circ}\right.$, and $90^{\circ}$ along the extruded/rolled direction) as in Figure $1 \mathrm{~b}$; these samples were shaped with a gauge length of $17.5 \mathrm{~mm}$ and a gauge width of $5 \mathrm{~mm}$. Tensile tests were conducted on a SANSI UTM5000 instrument with a strain rate of $1.0 \times 10^{-3} \mathrm{~s}^{-1}$ at room temperature. The samples for the microstructure observation were taken from the middle of the sheets. The microstructures of the tested samples were observed using optical microscopy $(\mathrm{OM})$ and scanning electron microscopy (SEM). The samples for the OM test were polished and etched with a picric acid solution containing $1.5 \mathrm{~g}$ picric acid, $25 \mathrm{~mL}$ ethanol, $5 \mathrm{~mL}$ acetic acid, and $10 \mathrm{~mL}$ water. The samples for the SEM test were polished and etched with a nitric acid alcohol solution containing 4 vol. \% nitric acid. The size of the particles was counted using the open source software Image J. The average value of the subsphaeroidal particle radius was acquired by measuring the particle circumference. The method was adopted by calculating more than 100 particles in one image or all the particles in three images to obtain the average value and guarantee the accuracy of the data. Grain orientation and micro-texture characterization were performed using an Electron Backscattered Diffraction (EBSD) 
analysis combined with a HKL Channel 5 System in a field emission scanning electron microscope (JEOL JSM-7800F, JEOL Ltd., Tokyo, Japan), using a scan step-size of $0.4 \mathrm{~mm}$. The sample surfaces were electrochemically polished in a commercial AC2 solution. The secondary phase in the extruded alloy sheet was identified using transmission electron microscopy (TEM; Zeiss Libra 200 FE, Carl Zeiss, Jena, Germany). The test accelerating voltage was $200 \mathrm{kV}$.

\section{Results}

\subsection{Microstructure}

Figure 2 shows the typical microstructures of the extruded, rolled, and annealed alloy sheets. The initial extruded microstructure includes fine and large equiaxial grains (Figure 2a), which imply a complete recrystallization process during extrusion. The average grain size is calculated as $\sim 13.9 \mu \mathrm{m}$. After rolling, the grain size decreases from $\sim 13.9 \mu \mathrm{m}$ to $\sim 8.5 \mu \mathrm{m}$. A large fraction of the deformation twins is found in the rolled sample, as shown in Figure $2 \mathrm{~b}$. Rolling at $400{ }^{\circ} \mathrm{C}$ could not make the alloy sheet dynamically recrystallized. To obtain a unified microstructure, we employed an annealing process at $250^{\circ} \mathrm{C}$ for $10,30,60$, and $120 \mathrm{~min}$. The average grain size reaches a minimum of $\sim 6.5 \mu \mathrm{m}$ after 30 min of annealing, as shown in Figure 3d. Twins produced by rolling can become the nucleate site in static recrystallization (SRX) and promote the nucleation of new grains [18]. Grain refining is assumed to be SRX by deformed twins, which induces the recrystallization mechanism [19]. However, with the extension of the annealing time, some grains easily become coarse, as denoted by the yellow circles in Figure 2e,f. The average grain size gradually increases from $6.5 \mu \mathrm{m}$ to $10.7 \mu \mathrm{m}$. A uniform microstructure of rolled ATM610 alloy sheet is obtained under the annealing process at $250{ }^{\circ} \mathrm{C}$ for $30 \mathrm{~min}$. Therefore, the following examinations (including microstructure and mechanical properties) focus on ATM610 alloy sheets extruded and rolling-annealed for $30 \mathrm{~min}$.

The X-ray diffraction (XRD) patterns of ATM610 alloy sheets extruded, rolled, and rolling-annealed for $30 \mathrm{~min}$, as obtained from their cross-section perpendicular to the deformation direction, are displayed in Figure 3. The extruded and rolled alloys present a single phase of $\alpha-\mathrm{Mg}$, whereas the rolling-annealed alloy contains two phases: $\alpha-\mathrm{Mg}$, and $\mathrm{Mg}_{17} \mathrm{Al}_{12}$. The content of the $\mathrm{Mg}_{17} \mathrm{Al}_{12}$ phase is increased by annealing.

Figure 4 shows the SEM images of ATM610 alloy sheets extruded and rolling-annealed for $30 \mathrm{~min}$. The images of the alloy sheets rolling-annealed for 10, 60, and $120 \mathrm{~min}$ are omitted because this morphology is similar to that of a sample rolling-annealed for $30 \mathrm{~min}$. Unlike those in the extruded sample, fine particles are distributed uniformly in the matrix in the rolling-annealed sample as shown by the red arrow in the SEM images. This result is consistent with the XRD results in which more $\mathrm{Mg}_{17} \mathrm{Al}_{12}$ is found in the rolling-annealed alloy than in the extruded alloy. The average radius of the particles significantly decreases from $\sim 7.7 \mu \mathrm{m}$ to $\sim 1.4 \mu \mathrm{m}$.

Moreover, TEM is employed to investigate the precipitates of the alloy sheets. The bright-field TEM images of the extruded ATM610 alloy sheet are presented in Figure 5. A number of fine precipitates are dispersed uniformly on the Mg matrix. High-magnification TEM bright-field images observed with the incident beam along the [0001] zone axes of the Mg matrix are presented in Figure $5 \mathrm{~b}$. The alloy exhibits submicron intermetallic $\mathrm{Mg}_{17} \mathrm{Al}_{12}$ precipitates as red arrow marked, which are identified using EDS (inset of Figure $5 b$ ). This outcome is in accordance with the XRD results that the rolling-annealed alloy contains the $\mathrm{Mg}_{17} \mathrm{Al}_{12}$ phase. These precipitates appear to be globular with a size of $100-150 \mathrm{~nm}$. Nano-scale particles have the potential to improve mechanical properties. 

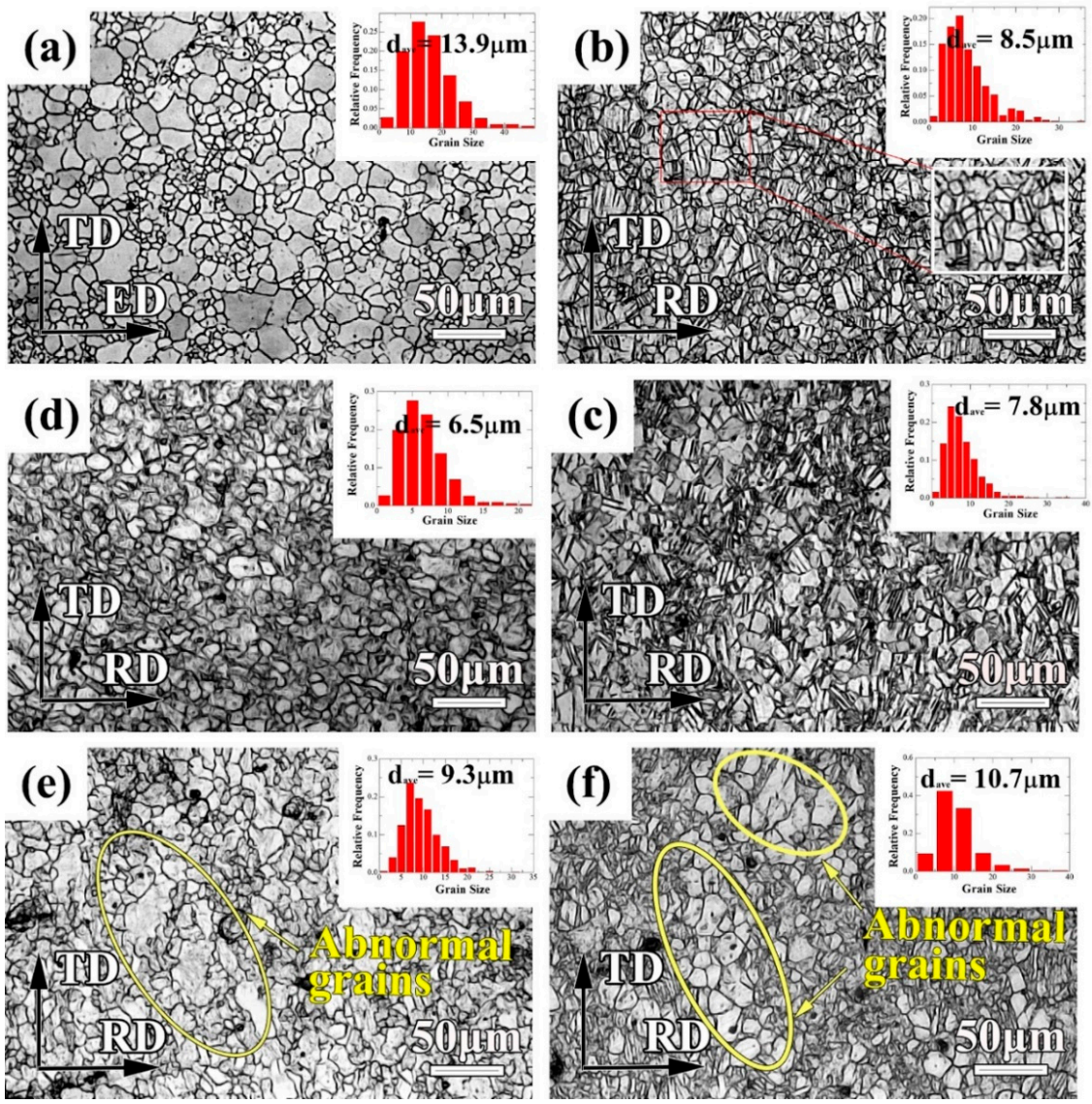

Figure 2. Optical microscopy (OM) of ATM610 alloy sheet at different conditions: (a) extruded sample, (b) as-rolled sample, (c) as-rolled sample annealed at $250{ }^{\circ} \mathrm{C}$ for $10 \mathrm{~min}$, (d) as-rolled sample annealed at $250{ }^{\circ} \mathrm{C}$ for $30 \mathrm{~min}$, (e) as-rolled sample annealed at $250{ }^{\circ} \mathrm{C}$ for $60 \mathrm{~min}$, and (f) as-rolled sample annealed at $250{ }^{\circ} \mathrm{C}$ for $120 \mathrm{~min}$.

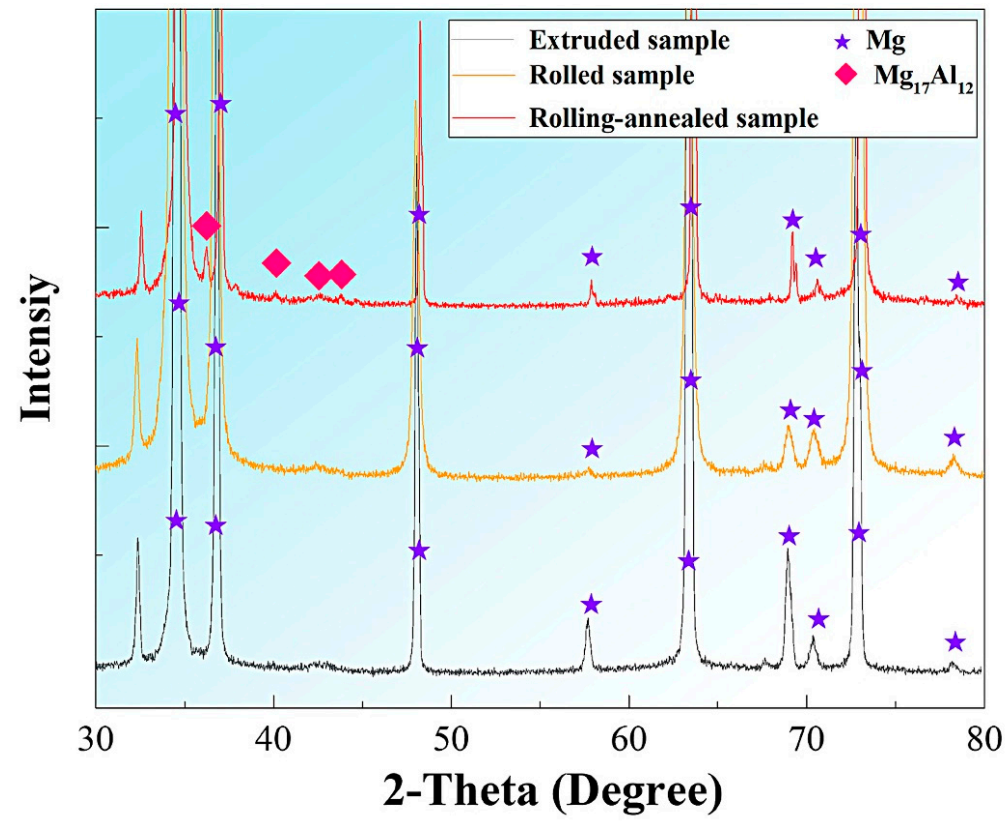

Figure 3. XRD patterns of ATM610 alloy sheets extruded, rolled, and rolling-annealed for $30 \mathrm{~min}$. 

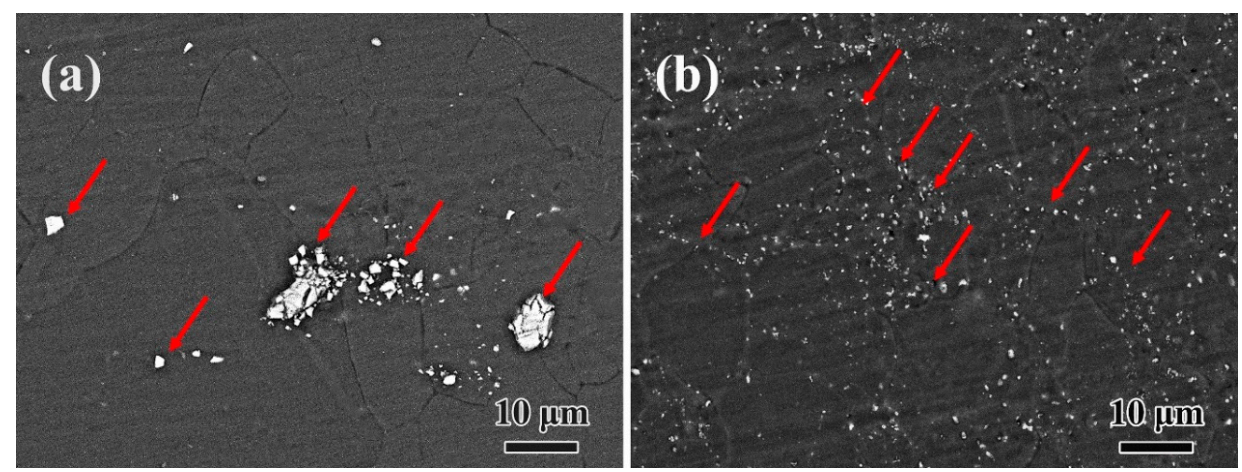

Figure 4. SEM micrographs of ATM610 alloy sheets: (a) extruded sample and (b) rolled sample annealed at $250{ }^{\circ} \mathrm{C}$ for $30 \mathrm{~min}$. The red arrows indicate $\mathrm{Mg}_{17} \mathrm{Al}_{12}$ particles.
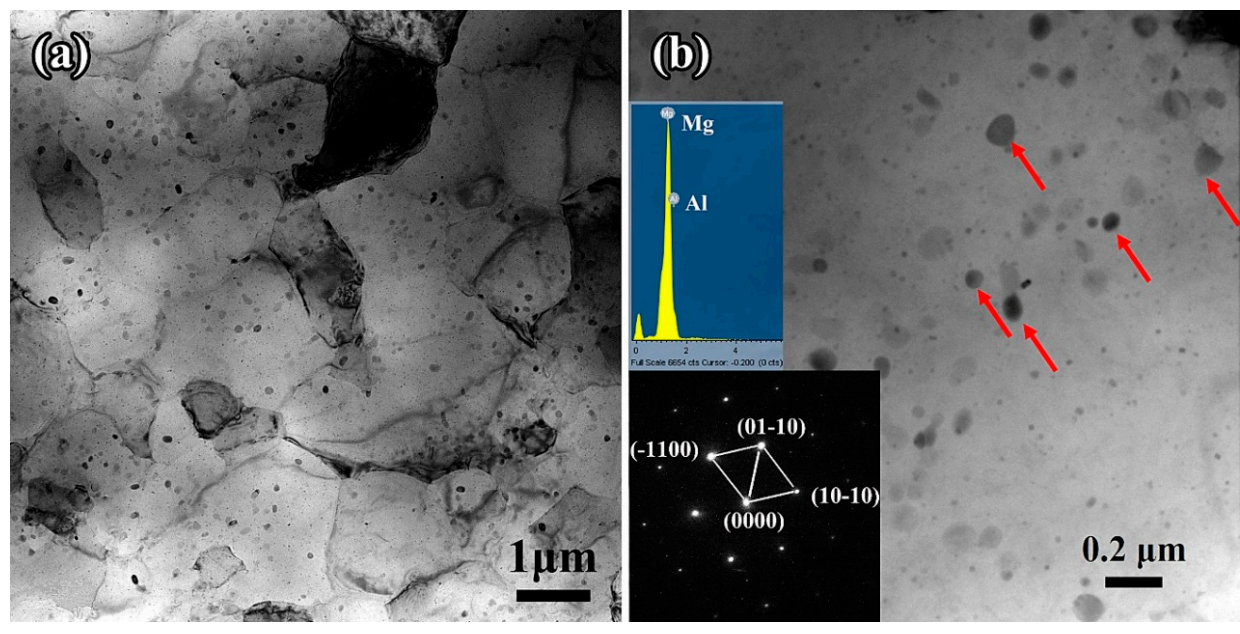

Figure 5. TEM images of extruded ATM610: (a) distribution of second phase and (b) shape of second phase.

Figure 6 shows the inverse pole figure (IPF) map and the corresponding (0002) pole figure of the ATM610 sheets. For the IPF maps, each of these colors are committed to a particular grain orientation. The color becomes varied after the rolling-annealed process, thus implying the rotation of the grain orientations. The average grain sizes of the extruded and rolling-annealed samples, which were measured using the Channel 5 software, are $14.3 \mu \mathrm{m}$ and $7.1 \mu \mathrm{m}$, respectively. The results of the grain size are consistent with the test using the statistical method from OM.

Finding twins in Figure $6 \mathrm{~b}$ is difficult due to the complete SRX through the $250{ }^{\circ} \mathrm{C} \times 30 \mathrm{~min}$ annealing. Full SRX leads to a highly uniform growth of recrystallized grains with randomized orientations [20]. Guan et al. [19] suggested that recrystallized grains generated from double twins contribute to texture modification. As shown in the (0002) pole figures, the samples display a typical basal texture, with the orientation of some grains slightly rotated from ND toward ED/RD. However, the orientation of some grains is in the ND or along TD after the rolling-annealed process. This condition causes the basal texture intensity to slightly decrease from 16.25 to 15.41. For magnesium alloys, the $(0001)<11 \overline{2} 0>$ slip is easy to slip in the early stages during the thermal processes. Prismatic slips and pyramidal slips can be activated when the temperature goes above $250{ }^{\circ} \mathrm{C}$. The c-axis of some grains tends to rotate toward the direction that deviates from the normal direction after the rolling-annealed process. This tendency may result in the activation of a prismatic <a> slip and a pyramidal $<\mathrm{c}+$ a $>$ slip, which cause the (0001) plane to rotate to ND. Fan et al. [21] suggested that the critical resolved shear stress of $\mathrm{a}<\mathrm{c}+\mathrm{a}>$ slip on pyramidal planes decreases significantly at a relatively 
elevated temperature. The non-basal slip system tends to be activated. Therefore, the basal texture intensity of the rolling-annealed alloy sheet is weakened.

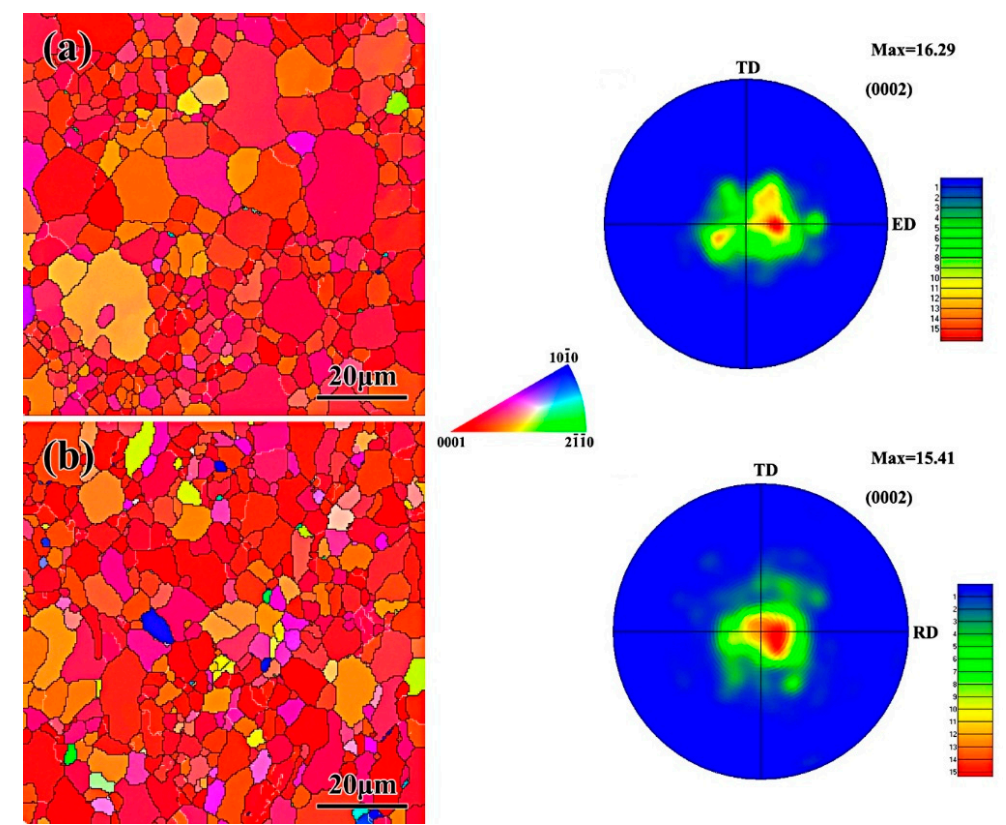

Figure 6. Inverse pole figure (IPF) map and (0002) pole figure of (a) extruded and (b) rolling-annealed sample annealed at $250{ }^{\circ} \mathrm{C}$ for $30 \mathrm{~min}$.

\subsection{Mechanical Properties}

The engineering stress-strain curves of the samples which were extruded and rolling-annealed for $30 \mathrm{~min}$ and obtained in the $0^{\circ}, 45^{\circ}$, and $90^{\circ}$ directions are illustrated in Figure $7 \mathrm{a}, \mathrm{b}$, respectively. The yield strength (YS), ultimate tensile strength (UTS), and fracture elongation (FE) of the three directions are summarized in Figure $7 \mathrm{c}$ and Table 1. Compared with the extruded sample, the rolling-annealed sample exhibits higher YS (223 MPa), UTS (313 MPa), and FE (25.2\%) at room temperature. The rolling-annealed ATM610 alloy sheet exhibits parallel UTS but superior ductility than the other extrusion-rolled Mg alloy sheets reported in the literature (e.g., Mg-5.3Zn-0.5Ce/La [15], and $\mathrm{Mg}-8 \mathrm{Li}-1 \mathrm{Al}$ ) [22].
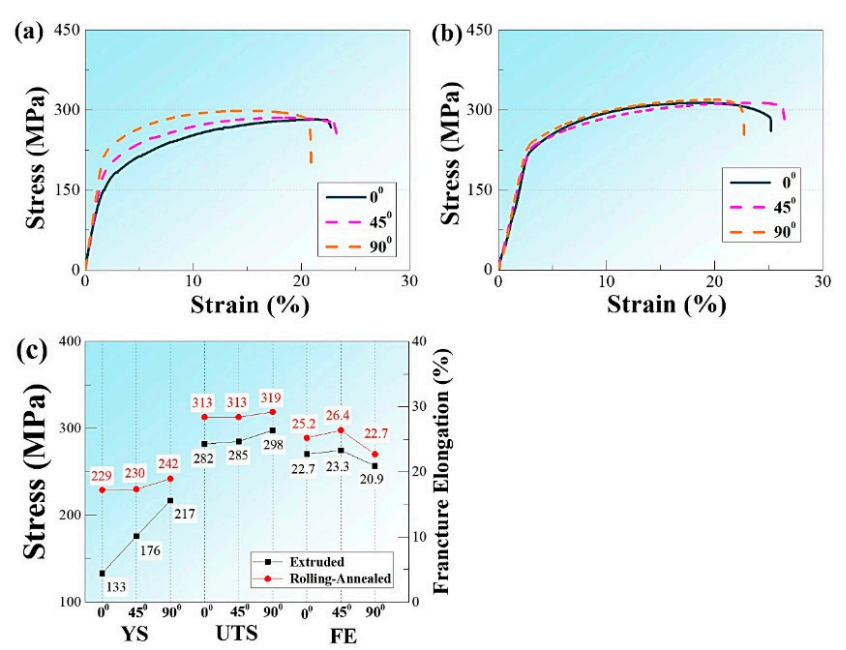

Figure 7. Mechanical properties of ATM610 alloy sheets. (a) extruded sample, (b) rolling-annealed sample, and (c) statistical data. 
Table 1. Tensile properties of ATM610 alloy sheets at room temperature in different loading directions.

\begin{tabular}{lccccccccc}
\hline \multirow{2}{*}{ ATM610 } & \multicolumn{3}{c}{ RD } & \multicolumn{3}{c}{$\mathbf{4 5}^{\circ}$} & \multicolumn{3}{c}{ TD } \\
\cline { 2 - 9 } & YS (MPa) & UTS (MPa) & FE (\%) & YS (MPa) & UTS (MPa) & FE (\%) & YS (MPa) & UTS (MPa) & FE (\%) \\
\hline $\begin{array}{l}\text { Extruded } \\
\begin{array}{l}\text { Rolling- } \\
\text { annealed }\end{array}\end{array}$ & $133 \pm 1.3$ & $282 \pm 1.8$ & $22.7 \pm 0.7$ & $176 \pm 1.7$ & $285 \pm 2.5$ & $23.3 \pm 1.0$ & $217 \pm 2.8$ & $298 \pm 0.8$ & $20.9 \pm 1.7$ \\
\hline
\end{tabular}

\section{Discussion}

Grain and particle refinement can contribute to the improvement of the YS of metallic materials. In the current study, according to the Hall-Petch relationship, $\Delta \sigma_{\text {grain }}=\mathrm{kd}^{-1 / 2}$, where $d$ is the average grain size that refines from $\sim 13.9 \mu \mathrm{m}$ to $\sim 6.5 \mu \mathrm{m}$ and $k$ is a constant of $0.29 \mathrm{MPa} \mathrm{m}^{1 / 2}$ [23]. The strength contributions from the grain boundaries of the samples extruded and rolling-annealed for $30 \mathrm{~min}$ are 77.8 and $113.7 \mathrm{MPa}$, respectively. This result reveals that the rolling process generates a visible enhancement in grain boundary strength. Moreover, many fine particles dispersed on the matrix can inhibit the dislocation motion, which is known to increase YS through the Orowan mechanism [24]. Hence, the improvement in the YS of the rolling-annealed sample should be mainly attributed to the grain refinement during the rolling process and the increased number of fine $\mathrm{Mg}_{17} \mathrm{Al}_{12}$ particles $[25,26]$. The elongation of the rolling-annealed sample is greater than that of the extruded sample because of the weak texture, fine grains, and fine $\mathrm{Mg}_{17} \mathrm{Al}_{12}$ precipitates. Rolling at $400{ }^{\circ} \mathrm{C}$ can improve the solid solubility of the $\mathrm{Sn}$ element in the $\mathrm{Mg}-\mathrm{Al}$ series alloy. More $\mathrm{Sn}$ atoms in the $\mathrm{Mg}$ matrix may be beneficial for reducing the stacking fault energies and improving the plastic deformation ability [13].

The Lankford value ( $r$-value) has a great effect on the anisotropy of magnesium alloy sheets. Therefore, the $r$-value is respectively given by [27]

$$
\begin{gathered}
r=\frac{\varepsilon_{w}}{\varepsilon_{t}} \\
\bar{r}=\left|\frac{r_{0^{\circ}}+r_{90^{\circ}}+2 r_{45^{\circ}}}{4}\right| \\
\Delta r=\left|\frac{r_{0^{\circ}}+r_{90^{\circ}}-2 r_{45^{\circ}}}{2}\right|
\end{gathered}
$$

where $\varepsilon_{t}$ is the thickness direction strain and $\varepsilon_{w}$ is the width direction strain. The $\bar{r}$ is the average $r$-value, and the $\Delta r$ is the planar anisotropy of the $r$-value.

Figure 8 shows a higher $r$-value along the TD than along the RD in the alloy sheets. This behavior refers to the particular texture, which exhibits basal orientation grains randomly distributed toward the $\mathrm{RD}$ rather than toward the TD (Figure 6). A similar tendency is observed in the AZ31 magnesium alloy sheet [28]. Moreover, the rolling-annealed sample displays significantly smaller $r$-values in three directions compared with the extruded sample. For wrought magnesium alloy with a relatively typical basal texture, the basal slip is hard to activate. Thus, the strain in the width direction is coordinated by the prismatic <a> slip, whereas the strain in the thickness direction is coordinated by the pyramidal $<\mathrm{c}+\mathrm{a}>$ slip and twinning. This will bring a large $r$-value. Otherwise, the $r$-value will decrease. The distributions of the grain boundary misorientation taken from an IPF image (as shown in Figure 6) are summarized in Figure 9. The rolling-annealed sample exhibits a higher relative frequency of high-angle grain boundary than the extruded sample. This result implies a highly dispersed orientation of the grains. In the case of the AZ31 magnesium alloy sheets $[29,30]$, the weak texture is responsible for the low average $r$-value. Thus, the random distribution of grains contributes to the isotropic plastic strain (low average $r$-value) of the rolling-annealed sample. The appropriate processes of extrusion combined with rolling contribute to a weak texture, fine grains, and fine $\mathrm{Mg}_{17} \mathrm{Al}_{12}$ particles, all of which are critical in realizing enhanced strength without losing ductility. 


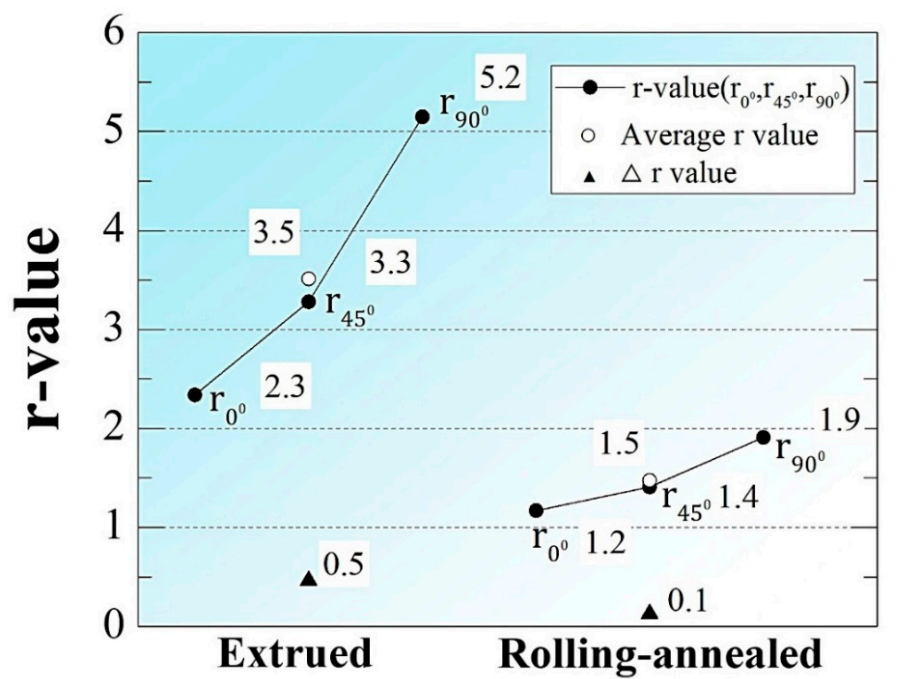

Figure 8. The $r$-value of ATM610 alloy sheets.

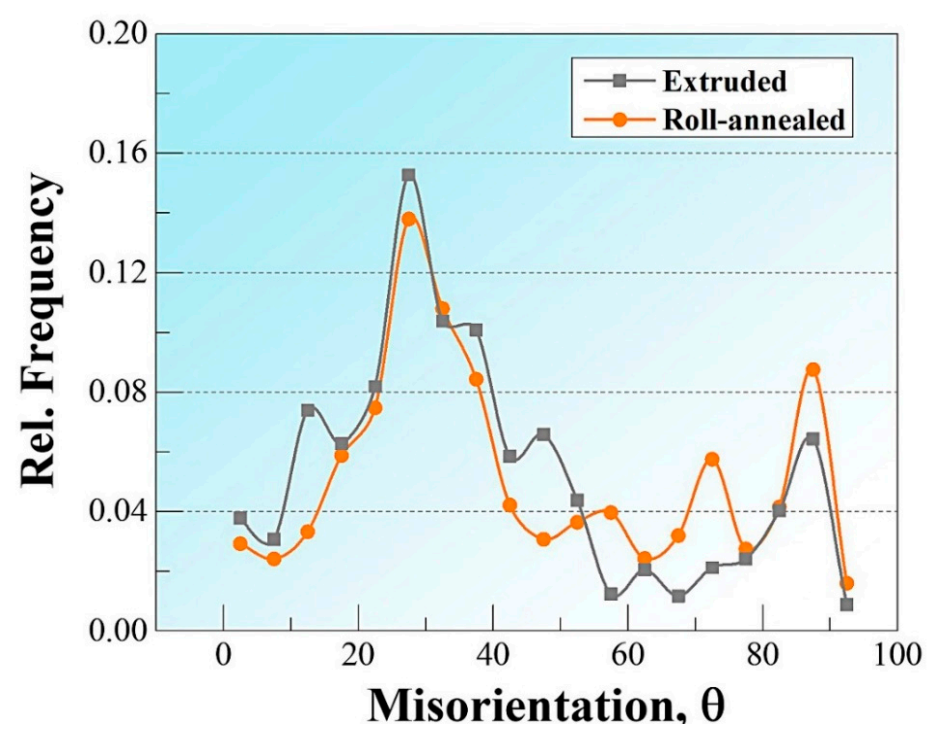

Figure 9. Distributions of grain boundary misorientations of the extruded sample and the rolling-annealed sample.

\section{Conclusions}

In this study, the microstructure evolution and mechanical properties, especially anisotropy, of ATM610 alloy sheets were investigated through extrusion combined with rolling. Both the strength and the anisotropy of the as-extruded alloy sheet improved through the rolling-annealed processes without losing any ductility. The significant improvement through the rolling-annealed process is attributed to the random grain orientation during the hot processes, and the refinement of the grains and particle microstructure.

(1) The YS, UTS, FE, and $\Delta r$-value of the rolling-annealed ATM610 alloy sheet were $229 \mathrm{MPa}, 313 \mathrm{MPa}$, $25.2 \%$, and 0.1 , respectively.

(2) The refined grains of the rolling-annealed alloy sheet with random orientation were mainly attributed to the SRX by deformed twins, which provided nucleation sites for the recrystallized grains during annealing.

(3) The refinement of the $\mathrm{Mg}_{17} \mathrm{Al}_{12}$ particles in the rolling-annealed alloy sheet is attributed to the rolling process, which breaks up large-scale particles in the as-extruded sheet. 
(4) The presence of fine grains with a random orientation and a large number of fine $\mathrm{Mg}_{17} \mathrm{Al}_{12}$ precipitates mainly explains the high strength and low yield anisotropy.

Author Contributions: Conceptualization, A.T. and F.P.; data curation, J.S. (Jiangfeng Song); formal analysis, P.P. and J.S. (Jia She); funding acquisition, A.T.; investigation, P.P. and S.Z.; methodology, P.P. and J.S. (Jia She); project administration, A.T.; resources, X.C.; supervision, A.T. and X.C.; validation, S.Z.; writing一original draft, P.P.; writing - review and editing, A.T. and J.S. (Jia She).

Funding: This research was funded by the National Key Research and Development Program of China (2016YFB0301100), the Natural Science Foundation of Chongqing (cstc2017jcyjBX0040), and the Graduate Research and Innovation Foundation of Chongqing, China (CYB18005).

Acknowledgments: The authors acknowledge the Research Group of National Engineering Research Center for Magnesium Alloys at Chongqing University.

Conflicts of Interest: The authors declare no conflicts of interest.

\section{References}

1. Alaneme, K.K.; Okotete, E.A. Enhancing plastic deformability of Mg and its alloys-A review of traditional and nascent developments. J. Magn. Alloy. 2017, 5, 460-475. [CrossRef]

2. Rashad, M.; Pan, F.; Liu, Y.; Chen, X.; Lin, H.; Pan, R.; Asif, M.; She, J. High temperature formability of graphene nanoplatelets-AZ31 composites fabricated by stir-casting method. J. Magn. Alloy. 2016, 4, 270-277. [CrossRef]

3. Wang, B.; Chen, X.; Pan, F.; Mao, J. Effects of Sn addition on microstructure and mechanical properties of Mg-Zn-Al alloys. Prog. Nat. Sci. Mater. Int. 2017, 27, 695-702. [CrossRef]

4. You, S.; Huang, Y.; Kainer, K.U.; Hort, N. Recent research and developments on wrought magnesium alloys. J. Magn. Alloy. 2017, 5, 239-253. [CrossRef]

5. Wang, G.; Huang, G.; Chen, X.; Deng, Q.; Tang, A.; Jiang, B.; Pan, F. Effects of Zn addition on the mechanical properties and texture of extruded Mg-Zn-Ca-Ce magnesium alloy sheets. Mater. Sci. Eng. A 2017, 705, $46-54$. [CrossRef]

6. Hu, Y.; Zhang, C.; Meng, W.; Pan, F.; Zhou, J. Microstructure, mechanical and corrosion properties of Mg-4Al-2Sn-xY-0.4Mn alloys. J. Alloy. Compd. 2017, 727, 491-500. [CrossRef]

7. El Mahallawy, N.; Ahmed Diaa, A.; Akdesir, M.; Palkowski, H. Effect of Zn addition on the microstructure and mechanical properties of cast, rolled and extruded Mg-6Sn-xZn alloys. Mater. Sci. Eng. A 2017, 680, 47-53. [CrossRef]

8. Wang, B.; Pan, F.; Chen, X.; Guo, W.; Mao, J. Microstructure and mechanical properties of as-extruded and as-aged Mg-Zn-Al-Sn alloys. Mater. Sci. Eng. A 2016, 656, 165-173. [CrossRef]

9. Sasaki, T.T.; Elsayed, F.R.; Nakata, T.; Ohkubo, T.; Kamado, S.; Hono, K. Strong and ductile heat-treatable Mg-Sn-Zn-Al wrought alloys. Acta Mater. 2015, 99, 176-186. [CrossRef]

10. Xu, D.; Han, E.H.; Xu, Y. Effect of long-period stacking ordered phase on microstructure, mechanical property and corrosion resistance of Mg alloys: A. review. Prog. Nat. Sci. Mater. Int. 2016, 26, 117-128. [CrossRef]

11. Liu, P.; Jiang, H.; Cai, Z.; Kang, Q.; Zhang, Y. The effect of Y., Ce and Gd on texture, recrystallization and mechanical property of Mg-Zn alloys. J. Magn. Alloy. 2016, 4, 188-196. [CrossRef]

12. Sasaki, T.T.; Yamamoto, K.; Honma, T.; Kamado, S.; Hono, K. A high-strength Mg-Sn-Zn-Al alloy extruded at low temperature. Scr. Mater. 2008, 59, 1111-1114. [CrossRef]

13. Wang, H.Y.; Zhang, N.; Wang, C.; Jiang, Q.C. First-principles study of the generalized stacking fault energy in Mg-3Al-3Sn alloy. Scr. Mater. 2011, 65, 723-726. [CrossRef]

14. She, J.; Pan, F.; Zhang, J.; Tang, A.; Luo, S.; Yu, Z.; Song, K.; Rashad, M. Microstructure and mechanical properties of Mg-Al-Sn extruded alloys. J. Alloy. Compd. 2016, 657, 893-905. [CrossRef]

15. Tong, L.B.; Zhang, J.B.; Zhang, Q.X.; Jiang, Z.H.; Xu, C.; Kamado, S.; Zhang, D.P.; Meng, J.; Cheng, L.R.; Zhang, H.J. Effect of warm rolling on the microstructure, texture and mechanical properties of extruded Mg-Zn-Ca-Ce/La alloy. Mater. Charact. 2016, 115, 1-7. [CrossRef]

16. Li, R.G.; Nie, J.F.; Huang, G.J.; Xin, Y.C.; Liu, Q. Development of high-strength magnesium alloys via combined processes of extrusion, rolling and ageing. Scr. Mater. 2011, 64, 950-953. [CrossRef] 
17. Wang, H.Y.; Zhang, E.B.; Nan, X.L.; Zhang, L.; Guan, Z.P.; Jiang, Q.C. A comparison of microstructure and mechanical properties of $\mathrm{Mg}-9 \mathrm{Al}-1 \mathrm{Zn}$ sheets rolled from as-cast, cast-rolling and as-extruded alloys. Mater. Des. 2016, 89, 167-172. [CrossRef]

18. Farzadfar, S.A.; Martin, E.; Sanjari, M.; Essadiqi, E.; Yue, S. Texture weakening and static recrystallization in rolled Mg-2.9Y and Mg-2.9Zn solid solution alloys. J. Mater. Sci. 2012, 47, 5488-5500. [CrossRef]

19. Guan, D.; Rainforth, W.M.; Ma, L.; Wynne, B.; Gao, J. Twin recrystallization mechanisms and exceptional contribution to texture evolution during annealing in a magnesium alloy. Acta Mater. 2017, 126, 132-144. [CrossRef]

20. Zeng, Z.R.; Zhu, Y.M.; Xu, S.W.; Bian, M.Z.; Davies, C.H.J.; Birbilis, N.; Nie, J.F. Texture evolution during static recrystallization of cold-rolled magnesium alloys. Acta Mater. 2016, 105, 479-494. [CrossRef]

21. Fan, H.; Tang, J.; Tian, X.; Wang, Q.; Tian, X.; El-Awady, J.A. Core structures and mobility of $\langle c\rangle$ dislocations in magnesium. Scr. Mater. 2017, 135, 37-40. [CrossRef]

22. Meng, X.; Wu, R.; Zhang, M.; Wu, L.; Cui, C. Microstructures and properties of superlight Mg-Li-Al-Zn wrought alloys. J. Alloy. Compd. 2009, 486, 722-725. [CrossRef]

23. Ono, N.; Nowak, R.; Miura, S. Effect of deformation temperature on Hall-Petch relationship registered for polycrystalline magnesium. Mater. Lett. 2004, 58, 39-43. [CrossRef]

24. Fu, H.; Guo, J.; Wu, W.; Liu, B.; Peng, Q. High pressure aging synthesis of a hexagonal Mg2Sn strengthening precipitate in Mg-Sn alloys. Mater. Lett. 2015, 157, 172-175. [CrossRef]

25. Ryen, Ø.; Nijs, O.; Lander, E.S.; Bjrn, H.; Nes, E. Strengthening Mechanisms in Solid Solution Aluminum Alloys. Metall. Mater. Trans. 2006, 37, 1999-2006. [CrossRef]

26. Yu, H.; Kim, Y.M.; You, B.S.; Yu, H.S.; Park, S.H. Effects of cerium addition on the microstructure, mechanical properties and hot workability of ZK60 alloy. Mater. Sci. Eng. A 2013, 559, 798-807. [CrossRef]

27. Chino, Y.; Sassa, K.; Kamiya, A.; Mabuchi, M. Stretch formability at elevated temperature of a cross-rolled AZ31 Mg alloy sheet with different rolling routes. Mater. Sci. Eng. A 2008, 473, 195-200. [CrossRef]

28. Bohlen, J.; Nürnberg, M.R.; Senn, J.W.; Letzig, D.; Agnew, S.R. The texture and anisotropy of magnesium-zinc-rare earth alloy sheets. Acta Mater. 2007, 55, 2101-2112. [CrossRef]

29. Agnew, S.R.; Duygulu, Ö. Plastic anisotropy and the role of non-basal slip in magnesium alloy AZ31B. Int. J. Plast. 2005, 21, 1161-1193. [CrossRef]

30. Lou, X.; Li, M.; Boger, R.; Agnew, S.; Wagoner, R. Hardening evolution of AZ31B Mg sheet. Int. J. Plast. 2007, 23, 44-86. [CrossRef] 